\title{
Becquerel per Liter
}

National Cancer Institute

\section{Source}

National Cancer Institute. Becquerel per Liter. NCI Thesaurus. Code C71165.

A metric unit of volumetric radioactivity concentration defined as a concentration of a radionuclide with an activity equal to one becquerel per unit volume equal to one liter. 